\title{
Avaliação de Características Agronômicas e Morfológicas das Gramíneas Forrageiras Marandu, Setária e Tanzânia aos 35 Dias de Crescimento nas Estações do Ano ${ }^{1}$

\author{
Luciana Gerdes ${ }^{2}$, Joaquim Carlos Werner ${ }^{3}$, Maria Tereza Colozza ${ }^{4}$, Dora Duarte de Carvalho ${ }^{4}$, \\ Eliana Aparecida Schammass ${ }^{4}$
}

\begin{abstract}
RESUMO - Foi realizado um experimento de campo em blocos completos ao acaso, em esquema de parcelas subdivididas, com 12 repetições, com o objetivo de comparar, no capim-marandu (Brachiaria brizantha Stapf. cv. Marandu), no capim-setária (Setaria sphacelata (Schum.) Moss var. sericea (Stapf.) cv. Kazungula) e no capim-tanzânia (Panicum maximum Jacq. cv. Tanzânia-1), a produção de matéria seca, os teores de matéria seca, a altura do relvado, a porcentagem de lâminas foliares e a altura do meristema apical, em cortes aos 35 dias de crescimento, nas estações de primavera (21/11 a 25/12/97), verão (29/12/97 a 02/02/98), outono (13/04 a 18/05/98) e inverno (28/05 a 01/07/98). As parcelas eram representadas pelas gramíneas forrageiras e as subparcelas, pelas estações do ano. OTanzânia apresentou sempre elevada porcentagem de lâminas foliares e baixo crescimento do meristema apical mostrando maiores produções no outono e, na primavera e no inverno, produções não diferentes das outras gramíneas, que também não diferiram entre si nas quatro estações. A setária apresentou os menores teores de matéria seca, independentemente das estações do ano, e a menor porcentagem de folhas, na primavera e no verão, o que pode limitar o seu consumo pelos animais.
\end{abstract}

Palavras-chave: altura do relvado, lâminas foliares, meristema apical, produção de matéria seca, teores de matéria seca

\section{Evaluation of Agronomic and Morphologic Characteristics of the Grasses Brachiaria brizantha cv. Marandu, Setaria sphacelata cv. Kazungula and Panicum maximum cv. Tanzania-1 at 35 Days of Growth in the Seasons of the Year}

\begin{abstract}
A field plot experiment was conducted in the Instituto de Zootecnia, Nova Odessa-SP, in a split plot design with 12 replicates, to compare, in the grasses marandu (Brachiaria brizantha Stapf. cv. Marandu), setaria (Setaria sphacelata cv. Kazungula) and tanzania (Panicum maximum cv. Tanzania-1): dry matter yield, dry matter percentage, sward height, leaf blade percentage, apical meristem height, in cuts at 35 days of growth, in the spring (21/11 to 25/12/97), summer (29/12/97 to 02/02/98), fall (13/04 to 18/05/98) and winter (28/05 to 01/07/98) seasons. The plots were the grasses and the split-plots the year seasons. Tanzania always showed high leaf blade percentage and low apical meristem height and presented the highest dry matter yield during fall season, and in the spring and winter, its dry matter yield did not differ from the other grasses, that were alike in the four seasons. The Setaria grass showed the smallest dry matter percentage in the four seasons, and the smallest leaf blade percentage, during spring and summer, which can limit its intake by the animals.
\end{abstract}

Key Words: apical meristem, dry matter content, dry matter yield, leaf blade, sward height

\section{Introdução}

A escolha da gramínea forrageira, para formação de uma pastagem, deve ser bastante criteriosa, visando maior produtividade de matéria seca e conteúdo de proteína bruta, com equilíbrio estacional e aceitabilidade pelos animais.

A produção de forragem é um dos principais fatores capazes de afetar a produtividade de um sistema de pastejo. Segundo CORSI e SANTOS (1995), o potencial de produção é a máxima produti- vidade biológica obtida sob condições ideais, sendo que a genética da planta forrageira define o potencial produtivo, enquanto o manejo é responsável pela expressão dessa característica.

Em detrimento da alta produção, as forrageiras tropicais apresentam estacionalidade bastante marcada, causando vários problemas, tanto na disponibilidade de alimentos para os animais, como na qualidade da forragem na época mais crítica do ano (PEDREIRA, 1973).

Ainda, CORSI e SANTOS (1995) comentam que, apesar de as forrageiras de clima tropical apre-

\footnotetext{
${ }^{1}$ Parte da Dissertação de Mestrado da primeira autora. Projeto Financiado pelo Tesouro do Estado de São Paulo e FAPESP.

2 Engo-Agro, MS em Nutrição Animal da FMVZ - USP, campus de Pirassununga e estagiária do Centro de Forragicultura e Pastagens do Instituto de Zootecnia, CP 60, CEP 13460-000, Nova Odessa/SP.

${ }^{3}$ Orientador da primeira autora e Pesquisador do Instituto de Zootecnia de Nova Odessa/SP.

${ }^{4}$ Pesquisador do Instituto de Zootecnia, CP 60, CEP 13460-000, Nova Odessa/SP, E-mail: cfp @ izsp.br
} 
sentarem potencial produtivo de matéria seca por hectare duas vezes maior que as gramíneas de clima temperado, a produtividade animal nos trópicos é baixa, principalmente devido à distribuição estacional da produção de forragem.

Gramíneas do gênero Brachiaria são largamente utilizadas em pastagens na América Tropical. Informações de MACEDO (1995) indicam cerca de 40 milhões de hectares cobertos por pastagens de braquiárias, formando extensos monocultivos, especialmente no Brasil Central e na Amazônia. Apesar da destacada representação da Brachiaria decumbens, entre as braquiárias, esta gramínea vem apresentando queda de produção após ciclos de pastejo, devido à degradação de suas pastagens. Atualmente, observa-se expansão da área cultivada com Brachiaria brizantha cv. Marandu, e os resultados evidenciam características promissoras.

Dentro do gênero Setaria, a Setaria sphacelata cv. Kazungula é uma gramínea tropical muito exigente em fertilidade, que apresenta condições de adaptação e boa produtividade em grande parte dos diferentes tipos de solo e de clima existentes no Brasil e seu plantio foi, por algum tempo, nas décadas de 60/70, bastante estimulado por suas excelentes características agronômicas. Entretanto, caiu em desuso, devido à presença de oxalatos em todos os cultivares, encontrados nas formas de oxalato de potássio, sódio ou cálcio e, também, na forma de ácido oxálico, constituintes considerados como fatores antinutricionais, limitando o consumo desta forrageira pelos animais (JONES e FORD, 1972).

A Setária despertou grande interesse nos pecuaristas, pelo bom desempenho em pastejo, boa capacidade de suporte e, especialmente, pelo razoável potencial de crescimento durante o período seco (CARRER et al., 1988).

Alguns cultivares de Panicum maximum estão entre as principais forrageiras cultivadas no Brasil. Os dados sobre a área ocupada pelos cultivares da espécie, no país, nem sempre são precisos, porém indicam serem eles bastante difundidos no território nacional. Pode-se estimar que a espécie já ocupou área superior a 6 milhões de hectares no Brasil (em sua grande maioria com o capim-colonião). Provavelmente, hoje, essa área seja menor, pois problemas de manejo e de fertilidade do solo têm prejudicado suas pastagens (ARONOVICH, 1995).

Entre os cultivares da espécie Panicum maximum, o plantio de tanzânia-1 tem sido bastante estimulado (ARONOVICH, 1995) por suas excelentes características agronômicas e de consumo pelos animais.
O presente trabalho teve como objetivo realizar um estudo comparativo de algumas características agronômicas e morfológicas do capim-marandu (Brachiaria brizantha Stapf. cv. Marandu), do capim-setária (Setaria sphacelata (Schum.) Moss var. sericea (Stapf.) cv. Kazungula) e do capimtanzânia (Panicum maximum Jacq. cv.Tanzânia-1) em cortes realizados aos 35 dias de crescimento, nas quatro estações do ano.

\section{Material e Métodos}

O experimento foi conduzido no Instituto de Zootecnia, Nova Odessa, São Paulo.

Estudaram-se o capim-marandu (Brachiaria brizantha Stapf. cv. Marandu), o capim-setária (Setaria sphacelata (Schumach) Moss var. sericea (Stapf.) cv. Kazungula) e o capim-tanzânia (Panicum maximum Jacq. cv. Tanzânia-1) semeados em parcelas

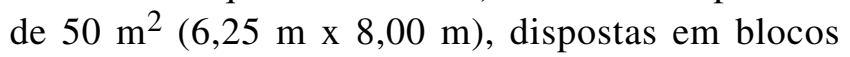
completos ao acaso, com 12 repetições.

Para correção do solo, a fim de elevar a saturação por bases a $50 \%$, foram aplicadas, em meados de setembro/96, 3 t de calcário dolomítico/ha.

A adubação de plantio, na base de $100 \mathrm{~kg} \mathrm{de} \mathrm{P}_{2} \mathrm{O}_{5} /$ ha, foi feita usando-se $556 \mathrm{~kg} / \mathrm{ha}$ de FOSMAG-464, que contém os seguintes constituintes químicos: $18 \%$ de $\mathrm{P}_{2} \mathrm{O}_{5}, 14 \%$ de $\mathrm{Ca}, 3,5 \%$ de $\mathrm{Mg}, 10 \%$ de $\mathrm{S}, 0,15 \%$ de $\mathrm{B}, 0,65 \%$ de $\mathrm{Zn}$ e $0,18 \%$ de $\mathrm{Cu}$. Misturou-se o adubo fosfatado com as sementes das gramíneas no momento da semeadura. Nitrogênio (100 kg N/ha) e potássio ( $60 \mathrm{~kg} \mathrm{~K}_{2} \mathrm{O} / \mathrm{ha}$ ) foram aplicados em cobertura trinta dias após o plantio, como sulfato de amônio e cloreto de potássio, respectivamente.

A densidade de semeadura foi baseada no valor cultural (VC\%) de cada espécie, usando-se 12; 8; e $16 \mathrm{~kg}$ de sementes/ha, respectivamente, para capimmarandu, capim-setária e capim-tanzânia, os quais foram semeados manualmente em sulcos espaçados de $31 \mathrm{~cm}$, em 21 de fevereiro/97. Os dados de precipitação pluviométrica no período experimental constam da Figura 1.

A cada sete dias, a partir da data de semeadura, foram feitas leituras do número de plantas e número de perfilhos por metro linear, até os 35 dias. Aos 145 dias de crescimento, foi feito um corte, considerado de estabelecimento. Os dados obtidos foram objeto de outro artigo científico.

Depois de que estabelecidas as três espécies estudadas, iniciaram-se os cortes para quantificar a produtividade e algumas características agronômicas 


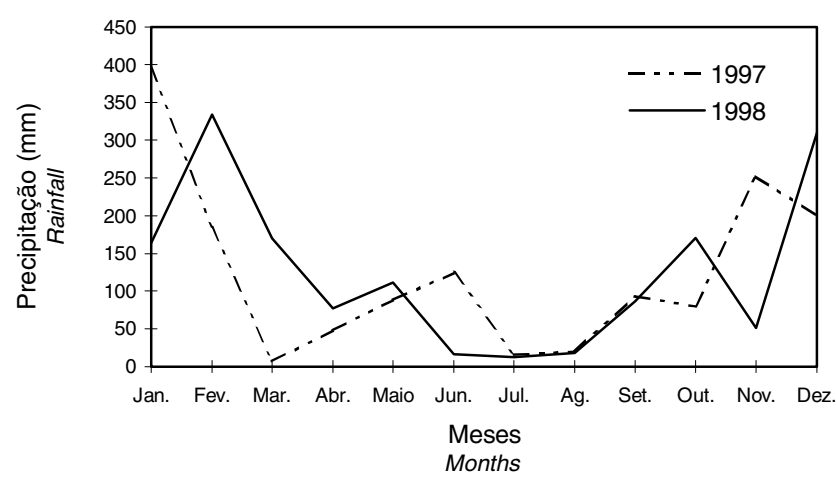

Figura 1 - Dados de precipitação pluviométrica no período experimental.

Figure 1 - Monthly rainfall data, in the experimental period.

e morfológicas das gramíneas, aos 35 dias de crescimento, nas estações de primavera (21/11 a 25/12/97), verão (29/12/97 a 02/02/98), outono (13/04 a 18/05/98) e inverno (28/05 a 01/07/98). No início do primeiro período de crescimento (primavera), as gramíneas foram roçadas a $15 \mathrm{~cm}$ de altura e, no final de cada período, após as amostragens, foram pastejadas e, novamente, rebaixadas mecanicamente $(15 \mathrm{~cm})$ no início do período de crescimento seguinte. No início do crescimento de outono (13/04/98), foram repetidas as adubações com $\mathrm{N}$ e $\mathrm{K}$.

As variáveis medidas nestes cortes foram: produção de matéria seca, teor de matéria seca, porcentagem de lâminas foliares na planta, altura do relvado e altura do meristema apical. Estas medições foram feitas em quatro pontos dentro de cada parcela, por meio do lançamento, ao acaso, de um quadrado de $0,5 \times 0,5 \mathrm{~m}\left(0,25 \mathrm{~m}^{2}\right)$.

Antes de executar cada corte, mediu-se a altura das plantas marcando-se a distância do solo à altura máxima do relvado, sem modificar a estrutura, ou seja, sem esticar ou comprimir as plantas. Esta altura foi medida ao lado dos quatro pontos demarcados aleatoriamente com o quadrado, usado para demarcação das áreas a serem amostradas.

O corte foi feito com tesoura de poda, e a altura de corte, para avaliação da produção de matéria seca e porcentagem de lâminas, foi a $15 \mathrm{~cm}$ do solo. $\mathrm{O}$ material verde colhido nos quatro pontos de cada parcela foi juntado $\left(1 \mathrm{~m}^{2}\right)$ e pesado; deste, foi retirada amostra para pesagem e secagem em estufa de circulação forçada de ar, regulada a $65^{\circ} \mathrm{C}$. Após secagem, até peso constante, as amostras foram novamente pesadas, para determinação do teor de matéria seca $\left(\% \mathrm{MS} 65^{\circ} \mathrm{C}\right)$ da planta inteira. Também, para a porcentagem de lâminas foliares, foram retira- das outras amostras do material verde colhido, para separação de lâminas e hastes de cada perfilho. Estas amostras foram colocadas em estufa para secagem $\left(65^{\circ} \mathrm{C}\right)$, sem, contudo, avaliar o seu peso verde. Em seguida, todas as amostras foram moídas, em moinho tipo Willey, com peneira de 40 mesh, acondicionadas em saquinhos plásticos, etiquetadas e encaminhadas ao laboratório para as determinações do teor de matéria seca a $105^{\circ} \mathrm{C}$ (SILVA, 1981).

Nas estações de verão e outono, simultaneamente à realização dos cortes, foram realizadas amostragens, em oito blocos, para medição da altura do meristema apical nas hastes das três gramíneas. Em um ponto aleatório, cortou-se, rente ao solo, ao lado de cada um dos quatro quadrados de amostragem, um feixe de perfilhos para composição de uma amostra em cada parcela. De cada amostra, retiraram-se dez perfilhos ao acaso, que foram cortados longitudinalmente, com canivete e, com auxílio de uma lupa, localizou-se a gema apical. A seguir, mediu-se, com auxílio de uma régua, a distância desta gema à base do colmo. Dessa maneira, cada observação de altura do meristema apical correspondeu à média de dez leituras.

O delineamento experimental adotado foi de blocos ao acaso em esquema de parcelas subdivididas para as variáveis em estudo, em que as parcelas eram representadas pelas gramíneas forrageiras e as subparcelas, pelas estações do ano, de acordo com o seguinte modelo estatístico:

$$
\underset{\text { em que }}{\mathrm{Y}_{\mathrm{ijk}}}=\mu+\gamma_{\mathrm{i}}+\beta_{\mathrm{j}}+\varepsilon_{\mathrm{ij}}+\pi_{\mathrm{k}}+\gamma \pi_{\mathrm{ik}}+\varepsilon_{\mathrm{ijk}} \text {, }
$$

$\mathrm{Y}_{\mathrm{ijk}}=$ variáveis dependentes: produção de matéria seca ${ }^{1}$, altura do relvado ${ }^{1}$, porcentagem de lâminas foliares $^{1}$, teor de matéria seca ${ }^{1}$, altura do meristema apical $^{2}$, ao $35^{\circ}$ dia de crescimento da gramínea i, no bloco j, na estação k;

$\mu=$ média da população;

$\gamma_{i}=$ efeito da gramínea $\mathrm{i}, \mathrm{i}=1,2,3$;

$\beta_{\mathrm{j}}=$ efeito do bloco $\mathrm{j}, \mathrm{j}^{1}=1,2, \ldots, 12 ; \mathrm{j}^{2}=1,2, \ldots, 8$;

$\varepsilon_{\mathrm{ij}}=$ erro aleatório associado a cada observação ij;

$\pi_{\mathrm{k}}=$ efeito da estação $\mathrm{k}, \mathrm{k}^{1}=1,2, \ldots, 4 ; \mathrm{k}^{2}=1,2$;

$\gamma \pi_{\mathrm{ik}}=$ efeito da interação entre gramínea i e estação k; e

$\varepsilon_{\mathrm{ijk}}=$ erro aleatório associado a cada observação ijk.

Foram utilizados os procedimentos GLM e ANOVA e as comparações das médias, por intermédio do teste Tukey a 5\%, do programa estatístico SAS - Institute (1989).

A variável altura do meristema apical não apresentou distribuição normal nem homogeneidade de variância e foi transformada em $\ln (x+1)$, para normalização dos dados e ou estabilização da variância. 


\section{Resultados e Discussão}

As produções de matéria seca dos capins-marandu, setária e tanzânia, cortados com 35 dias de crescimento, nas estações de primavera, verão, outono e inverno, no ano agrícola 97/98, são mostradas na Tabela 1.

Houve interação $(\mathrm{P}<0,05)$ gramíneas $\mathrm{x}$ estações do ano. Observou-se que, nas estações de primavera e inverno, as três gramíneas não diferiram $(\mathrm{P}>0,05)$ quanto às suas produções de massa seca. Na estação de verão, o Tanzânia mostrou-se mais produtivo $(\mathrm{P}<0,05)$, quando comparado ao Marandu, e a Setária não diferiu $(\mathrm{P}>0,05)$ do Marandu e do Tanzânia. Já no outono, a produção do Tanzânia foi maior $(\mathrm{P}<0,05)$ que as das outras duas gramíneas.

No estudo do efeito de estações, Marandu e Setária tiveram produções maiores $(\mathrm{P}<0,05)$ na primavera, intermediárias no verão e menores $(\mathrm{P}<0,05)$ no outono e inverno. Já as produções do Tanzânia não diferiram $(\mathrm{P}>0,05)$ na primavera e no verão. A produção do outono também não diferiu $(\mathrm{P}>0,05)$ do verão, mas foi menor $(\mathrm{P}<0,05)$ que a da primavera. Já as produções no inverno foram menores $(\mathrm{P}<0,05)$ que as produções nas três outras estações, destacando-se, nestas comparações, a boa produção do Tanzânia, principalmente no outono (Tabela 1).

VILLARREAL et al. (1994), estudando as características agronômicas de 16 gramíneas forrageiras, na Costa Rica, constataram produções de matéria seca (t/ha) de 1,35; 1,04; e 0,59 para P. maximum CIAT 6299, B. brizantha CIAT 6299 e S. sphacelata var. Morado (local), respectivamente, em crescimento de 35 dias, no período de chuvas, demonstrando a superioridade da espécie $P$. maximum sobre as demais. RUGGIERI et al. (1997) também encontraram maior produçãodo Tanzânia, quando comparado com Colonião e Marandu.

A seleção dos cultivares de $P$. maximum, visando à produção no período seco do ano, é uma preocupação para os pesquisadores que os lançam (JANK e SAVIDAN, 1985). Vinte e cinco acessos selecionados no CNPGC da EMBRAPA, entre eles o Tanzânia, produziram cerca de $14 \%$ na seca, em relação à produção total anual (SAVIDAN et al., 1990) contra 6\% do capim-colonião (JANK, 1994). Os resultados do presente trabalho comprovam o bom desempenho do Tanzânia relatados por SAVIDAN et al. (1990), JANK (1994) e RUGGIERI et al. (1997).

$\mathrm{Na}$ análise dos resultados da Tabela 2, verifica-se que os teores de matéria seca na primavera e no inverno foram mais elevados $(\mathrm{P}<0,05)$ para os cultivares Marandu e Tanzânia. No verão e no outono, o maior $(\mathrm{P}<0,05)$ teor foi do marandu, seguindo-se o do Tanzânia e, por último, com os menores $(\mathrm{P}<0,05)$ teores, a Setária. COSENTINO et al. (1985), estudando os teores de matéria seca $\left(65^{\circ} \mathrm{C}\right)$ nas gramíneas forrageiras kazungula, transvala, petrie, gatton panic, Pennisetum clandestinum e Paspalum sp, verificaram, também, menores teores para o kazungula.

Comparando os teores de matéria seca em cada gramínea, ao longo das estações (Tabela 2), verificase que, tanto a Setária quanto o Tanzânia, apresentaram os teores mais elevados $(\mathrm{P}<0,05)$ no inverno e os

Tabela 1 - Produção de matéria seca das gramíneas Marandu, Setária e Tanzânia amostradas aos 35 dias nas estações de primavera, verão, outono e inverno. Médias de doze repetições

Table 1 - Dry matter yield of the grasses Marandu, Setaria and Tanzania at 35 days of growth during spring, summer, fall and winter. Means of twelve replications

\begin{tabular}{|c|c|c|c|c|}
\hline \multirow[b]{2}{*}{$\begin{array}{l}\text { Capim } \\
\text { Grass }\end{array}$} & \multicolumn{4}{|c|}{$\begin{array}{c}\text { Produção de matéria seca - t/ha } \\
\text { Dry matter yield }\end{array}$} \\
\hline & $\begin{array}{l}\text { Primavera } \\
\text { Spring }\end{array}$ & $\begin{array}{c}\text { Verão } \\
\text { Summer }\end{array}$ & $\begin{array}{l}\text { Outono } \\
\text { Fall }\end{array}$ & $\begin{array}{l}\text { Inverno } \\
\text { Winter }\end{array}$ \\
\hline $\begin{array}{l}\text { Marandu } \\
\text { Setária } \\
\text { Tanzânia } \\
\end{array}$ & $\begin{array}{l}3,76^{\mathrm{Aa}} \\
3,38^{\mathrm{Aa}} \\
3,30^{\mathrm{Aa}}\end{array}$ & $\begin{array}{c}2,03^{\mathrm{Bb}} \\
2,56^{\mathrm{Bab}} \\
2,88^{\mathrm{ABa}} \\
\end{array}$ & $\begin{array}{l}1,19^{\mathrm{Cb}} \\
1,60^{\mathrm{Cb}} \\
2,35^{\mathrm{Ba}}\end{array}$ & $\begin{array}{l}0,95^{\mathrm{Ca}} \\
0,80^{\mathrm{Ca}} \\
1,10^{\mathrm{Ca}} \\
\end{array}$ \\
\hline $\begin{array}{l}\mathrm{CV} \% \text { (capins) } \\
\text { CV \% (grasses) } \\
\mathrm{CV} \%(\text { estações })\end{array}$ & \multicolumn{4}{|c|}{35,02} \\
\hline
\end{tabular}

Médias seguidas de mesma letra, minúscula nas colunas e maiúscula nas linhas, não diferem $(P>0,05)$ pelo teste Tukey.

Means followed by the same letter, small in the same column and capital in the same row, do not differ $(P>.05)$ by Tukey test. 
mais baixos $(\mathrm{P}<0,05)$ no outono, com teores intermediários na primavera e verão. Já no Marandu, nas estações de verão e inverno, os teores foram maiores $(\mathrm{P}<0,05)$ que na primavera e no outono.

Destacam-se os sempre mais baixos teores de matéria seca da Setária, o que, além de outros fatores, pode limitar o seu consumo pelos animais. EUCLIDES (1995), entre outros autores, mencionam que baixos teores de matéria seca em gramíneas forrageiras são um dos fatores que limita o consumo das mesmas pelos animais.

Na Tabela 3, são mostrados os dados de porcentagens de lâminas foliares das três gramíneas, amostradas aos 35 dias de crescimento, nas quatro estações. A interação gramíneas $\mathrm{x}$ estações foi significativa $(\mathrm{P}<0,05)$. No seu desdobramento, estudando-se gramíneas em cada estação, verifica-se que, na primavera e no verão, o Tanzânia apresentou a maior $(\mathrm{P}<0,05)$ porcentagem, seguido-se o Marandu e, por fim, a Setária. No outono, Tanzânia e Setária não diferiram $(\mathrm{P}>0,05)$ em suas porcentagens de lâminas, que foram menores $(\mathrm{P}<0,05)$ que as do Marandu. Finalmente, no inverno, as porcentagens de lâminas nas três gramíneas não diferiram $(\mathrm{P}>0,05)$.

A menor porcentagem de folhas da Setária coincide com rápida elevação do meristema apical, segundo dados observados por GERDES et al. (1998), em trabalho conduzido simultaneamente ao presente e na mesma área experimental. Tal condição não é desejada no manejo de uma pastagem, uma vez que a menor porcentagem de folhas compromete a qualidade da forragem (CORSI, 1988).

Cada espécie teve comportamento distinto ao lon- go das estações. O Marandu apresentou a maior $(\mathrm{P}<0,05)$ porcentagem de lâminas no outono e inverno e, conseqüentemente, menores $(\mathrm{P}<0,05)$ porcentagens na primavera e no verão. A Setária apresentou porcentagens diferentes $(\mathrm{P}<0,05)$ de estação para estação, na seguinte ordem decrescente: inverno, outono, primavera e verão. O Tanzânia também apresentou porcentagens maiores $(\mathrm{P}<0,05)$ no inverno, intermediárias no outono e menores nas estações de verão e primavera.

Tanto no outono quanto no inverno, nos quais houve menor crescimento (Tabela 1) das três gramíneas, a relação lâmina/haste foi bem superior $(\mathrm{P}<0,05)$ às das outras duas estações, como se pode observar na Tabela 3. Esta seqüência não foi, entretanto, observada por SANTOS (1997), que, estudando os cultivares Mombaça e Tanzânia, obteve maior participação das folhas (em intervalo entre cortes de 48 dias) no período de novembro/dezembro e a menor, em abril/maio. A baixa porcentagem de folhas em abril/maio deve-se, segundo a autora, à predominância de perfilhos reprodutivos neste período, com este intervalo de cortes.

Em avaliação agronômica de 401 acessos de Panicum maximum, JANK (1994) relatou que o capim-colonião apresentou, em média, $66 \%$ de folhas, sendo que $42 \%$ dos acessos apresentaram maior porcentagem de folhas que este cultivar. $\mathrm{O}$ Tanzânia teve porcentagem de folhas igual a $80 \%$, a qual foi semelhante aos obtidos para este cultivar, no presente trabalho, na primavera e no verão, porém inferior aos do outono e inverno.

Em estudo de seis ecotipos de P. maximum, compa-

Tabela 2 - Teores de matéria seca das gramíneas Marandu, Setária e Tanzânia amostradas aos 35 dias nas estações de primavera, verão, outono e inverno. Médias de doze repetições

Table 2 - Dry matter percentage of the grasses Marandu, Setaria and Tanzania at 35 days of growth during spring, summer, fall and winter. Means of twelve replications

\begin{tabular}{|c|c|c|c|c|}
\hline \multirow[b]{2}{*}{$\begin{array}{l}\text { Capim } \\
\text { Grass }\end{array}$} & \multicolumn{4}{|c|}{$\begin{array}{c}\text { Teores de matéria seca }(\%) \\
\text { Dry matter percentage }\end{array}$} \\
\hline & $\begin{array}{l}\text { Primavera } \\
\text { Spring }\end{array}$ & $\begin{array}{l}\text { Verão } \\
\text { Summer }\end{array}$ & $\begin{array}{l}\text { Outono } \\
\text { Fall }\end{array}$ & $\begin{array}{l}\text { Inverno } \\
\text { Winter }\end{array}$ \\
\hline $\begin{array}{l}\text { Marandu } \\
\text { Setária } \\
\text { Tanzânia }\end{array}$ & $\begin{array}{l}20,17^{\mathrm{Ba}} \\
13,82^{\mathrm{BCb}} \\
19,35^{\mathrm{Ba}}\end{array}$ & $\begin{array}{l}22,90^{\mathrm{Aa}} \\
14,68^{\mathrm{Bc}} \\
19,50^{\mathrm{Bb}}\end{array}$ & $\begin{array}{l}19,19^{\mathrm{Ba}} \\
12,96^{\mathrm{Cc}} \\
16,94^{\mathrm{Cb}}\end{array}$ & $\begin{array}{l}23,63^{\mathrm{Aa}} \\
17,07^{\mathrm{Ab}} \\
22,92^{\mathrm{Aa}}\end{array}$ \\
\hline $\begin{array}{l}\text { CV \% (capins) } \\
\text { CV \% (grasses) } \\
\text { CV \% (estações) } \\
\text { CV \% (seasons) }\end{array}$ & \multicolumn{4}{|c|}{4,01} \\
\hline
\end{tabular}

Médias seguidas de mesma letra, minúscula nas colunas e maiúscula nas linhas, não diferem $(P>0,05)$ pelo teste Tukey.

Means followed by the same letter, small in the same column and capital in the same row, do not differ $(P>.05)$ by Tukey test. 
Tabela 3 - Porcentagens de lâminas das gramíneas Marandu, Setária e Tanzânia amostradas aos 35 dias nas estações de primavera, verão, outono e inverno. Médias de doze repetições

Table 3 - Leaf blade percentage of the grasses Marandu, Setaria and Tanzania at 35 days of growth, during spring, summer, fall and winter. Means of twelve replications

\begin{tabular}{|c|c|c|c|c|}
\hline \multirow[b]{2}{*}{$\begin{array}{l}\text { Capim } \\
\text { Grass }\end{array}$} & \multicolumn{4}{|c|}{$\begin{array}{c}\text { Lâminas foliares }(\%) \\
\text { Leaf blade }\end{array}$} \\
\hline & $\begin{array}{l}\text { Primavera } \\
\text { Spring }\end{array}$ & $\begin{array}{l}\text { Verão } \\
\text { Summer }\end{array}$ & $\begin{array}{l}\text { Outono } \\
\text { fall }\end{array}$ & $\begin{array}{c}\text { Inverno } \\
\text { Winter }\end{array}$ \\
\hline $\begin{array}{l}\text { Marandu } \\
\text { Setária } \\
\text { Tanzânia }\end{array}$ & $\begin{array}{l}68,17^{\mathrm{Bb}} \\
47,25^{\mathrm{Cc}} \\
81,67^{\mathrm{Ca}}\end{array}$ & $\begin{array}{l}72,92^{\mathrm{Bb}} \\
38,00^{\mathrm{Dc}} \\
81,92^{\mathrm{Ca}}\end{array}$ & $\begin{array}{l}98,75^{\mathrm{Aa}} \\
88,67^{\mathrm{Bb}} \\
90,17^{\mathrm{Bb}}\end{array}$ & $\begin{array}{l}99,08^{\mathrm{Aa}} \\
95,83^{\mathrm{Aa}} \\
97,33^{\mathrm{Aa}}\end{array}$ \\
\hline $\begin{array}{l}\mathrm{CV} \% \text { (capins) } \\
\text { CV \% (grasses) } \\
\mathrm{CV} \% \text { (estações) } \\
\text { CV \% (seasons) }\end{array}$ & \multicolumn{4}{|c|}{2,47} \\
\hline
\end{tabular}

Médias seguidas de mesma letra, minúscula nas colunas e maiúscula nas linhas, não diferem $(P>0,05)$ pelo teste Tukey.

Means followed by the same letter, small in the same column and capital in the same row, do not differ $(P>.05)$ by Tukey test.

rados com os dois cultivares, Mombaça e Tobiatã, e com a B. brizantha cv. Marandu, EUCLIDES (1995) constatou maiores porcentagens de folhas nos da espécie Panicum, nos dois períodos do ano (água e seca).

JANK e SAVIDAN (1985) verificaram que o capim-colonião apresentou somente $39 \%$ de folhas nos quatro meses de seca, enquanto alguns acessos de $P$. maximum chegaram a apresentar até $91 \%$ de folhas.

Ressalta-se que, no presente trabalho, como o período de crescimento era sempre de 35 dias, no outono e inverno, a proporção de folhas era maior em relação à primavera e ao verão, devido ao menor ritmo de crescimento e, conseqüentemente, menor elongação do colmo naqueles dois períodos mais críticos do ano. Mesmo considerando-se os colmos como importantes para o rápido crescimento da pastagem (CORSI, 1988), acessos com elevada porcentagem de folhas são preferidos. Uma vez que os animais pastejam preferencialmente as folhas, características como elevados teores de matéria seca, baixo conteúdo de colmos e altas proporções de folhas são desejáveis (STOBBS, 1975).

A altura do relvado das três gramíneas variou $(\mathrm{P}<0,05)$ com a época do ano (Tabela 4). Na primavera e no verão, período em que houve o mais rápido crescimento, Setária e Tanzânia apresentaram as maiores $(\mathrm{P}<0,05)$ alturas. No outono, o Tanzânia apresentou o maior porte $(\mathrm{P}<0,05)$ entre as três gramíneas, seguindo-se a setária, com altura intermediária e, por último, com a menor $(\mathrm{P}<0,05)$ altura, o Marandu. No inverno, Tanzânia teve maior $(\mathrm{P}<0,05)$ altura que o Marandu e ambos não diferiram $(\mathrm{P}>0,05)$ da Setária.
Para o estudo do efeito de estações sobre as gramíneas (Tabela 4), o Marandu seguiu a sequiência decrescente $(\mathrm{P}<0,05)$ : primavera, verão, outono e inverno. A Setária e o Tanzânia foram afetados igualmente pelas estações, tendo suas maiores $(\mathrm{P}<0,05)$ alturas na primavera e no verão. No outono, as alturas destas duas gramíneas foram menores $(\mathrm{P}<0,05)$ do que naquelas duas estações, porém maiores $(\mathrm{P}<0,05)$ que as do inverno. No geral, a variação nas alturas dos relvados dos três capins, nas diversas estações do ano, seguiu a mesma tendência observada para a produção de matéria seca mostrada na Tabela 1 .

A altura do meristema apical só foi avaliada nas estações de verão e outono. A interação gramíneas x estações foi significativa $(\mathrm{P}<0,05)$. No seu desdobramento, quando se estuda a diferença entre as gramíneas em cada estação (Figura 2), verifica-se que a altura do meristema apical na Setária, com 35 dias de crescimento, é cerca de três vezes maior que a do Marandu, enquanto o meristema apical dos perfilhos do Tanzânia esteve praticamente rente ao solo. No outono, as alturas dos meristemas apicais do Marandu e da Setária não diferiram $(\mathrm{P}>0,05)$, enquanto os do Tanzânia estiveram com alturas mais baixas $(\mathrm{P}<0,05)$ que os da Setária, mas não diferiram $(\mathrm{P}>0,05)$ daquelas do Marandu. As alturas dos meristemas apicais encontrados no Tanzânia coincidem com as descritas por GOMIDE (1979) para o colonião, avaliado em torno de 35 dias.

Na Figura 3, é mostrada a altura dos meristemas apicais de cada gramínea em função das duas estações. Marandu e Setária apresentaram elevação rápida dos 
Rev. bras. zootec.

Tabela 4 - Altura do relvado dos capins Marandu, Setária e Tanzânia amostrados aos 35 dias nas estações de primavera, verão, outono e inverno. Médias de doze repetições

Table 4 - Sward height of the grasses Marandu, Setaria and Tanzania at 35 days of growth during spring, summer, autumn and winter. Means of twelve replications

\begin{tabular}{|c|c|c|c|c|}
\hline \multirow[b]{2}{*}{$\begin{array}{l}\text { Capins } \\
\text { Grasses }\end{array}$} & \multicolumn{4}{|c|}{$\begin{array}{l}\text { Altura do relvado }(\mathrm{cm}) \\
\text { Sward height }\end{array}$} \\
\hline & $\begin{array}{l}\text { Primavera } \\
\text { Spring }\end{array}$ & $\begin{array}{l}\text { Verão } \\
\text { Summer }\end{array}$ & $\begin{array}{l}\text { Outono } \\
\text { Autumn }\end{array}$ & $\begin{array}{l}\text { Inverno } \\
\text { Winter }\end{array}$ \\
\hline $\begin{array}{l}\text { Marandu } \\
\text { Setária } \\
\text { Tanzânia }\end{array}$ & $\begin{array}{l}67,67^{\mathrm{Ab}} \\
89,33^{\mathrm{Aa}} \\
83,75^{\mathrm{Aa}}\end{array}$ & $\begin{array}{l}46,83^{\mathrm{Bb}} \\
85,00^{\mathrm{Aa}} \\
77,75^{\mathrm{Aa}}\end{array}$ & $\begin{array}{l}36,17^{\mathrm{Cc}} \\
47,25^{\mathrm{Bb}} \\
58,42^{\mathrm{Ba}}\end{array}$ & $\begin{array}{l}25,92^{\mathrm{Db}} \\
27,83^{\mathrm{Cab}} \\
34,83^{\mathrm{Ca}}\end{array}$ \\
\hline $\begin{array}{l}\text { CV \% (capins) } \\
\text { CV \% (grasses) } \\
\text { CV \% (estações) } \\
\text { CV \% (seasons) }\end{array}$ & \multicolumn{4}{|c|}{7,19} \\
\hline
\end{tabular}
pelo teste Tukey.

Means followed by the same letter, small in the same column and capital in the same row, do not differ (P>.05) by Tukey test.

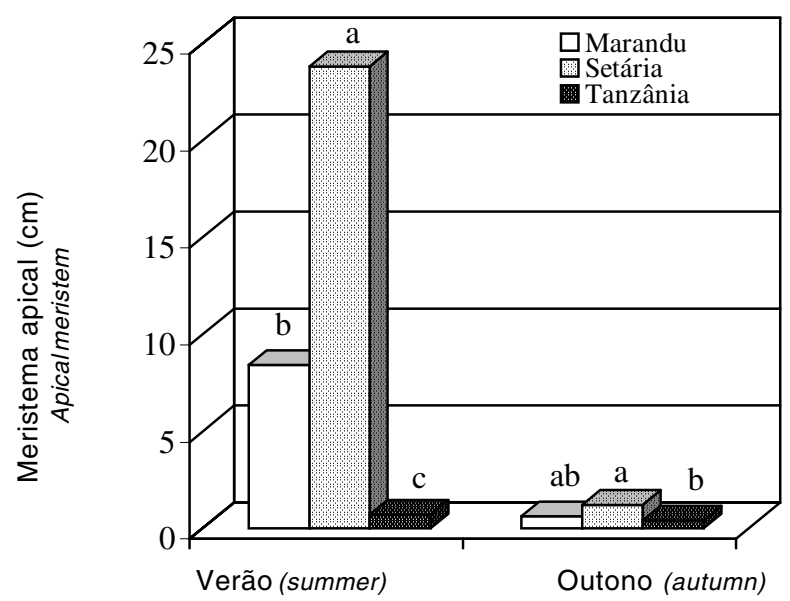

Figura 2 - Altura do meristema apical $(\mathrm{cm})$ das gramíneas Marandu, Setária e Tanzânia nas estações de verão e outono. Médias de oito repetições (Médias seguidas de mesma letra, para cada estação do ano, não diferem $(P>0,05)$ pelo teste Tukey. Dados analisados segundo a transformação logaritmo neperiano. As médias foram re-transformadas).

Figure 2 - Apical meristem height $(\mathrm{cm})$ of the grasses marandu, setaria and tanzania during the summer and fall seasons. Means of eight replications (Means followed by the same letters, in each season, do not differ $(P>.05)$ by Tukey test. Data were transformed by $\ln (x+1)$ for analysis. Means were back transformed).

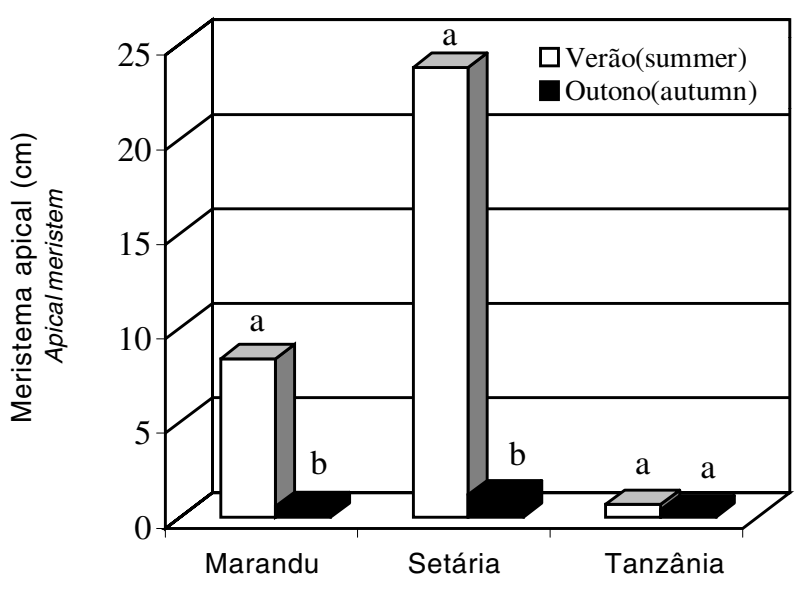

Figura 3 - Altura do meristema apical (cm) das gramíneas Marandu, Setária e Tanzânia nas estações de verão e outono. Médias de oito repetições (Médias seguidas de mesma letra, para cada capim, não diferem $(P>0,05)$ pelo teste $F$. Dados analisados segundo a transformação logaritmo neperiano. As médias foram re-transformadas).

Figure 3 - Apical meristem height $(\mathrm{cm})$ of the grasses marandu, setaria and tanzania during the summer and fall seasons. Means of eight replications (Means followed by the same letters, for each grass, do not differ $(P>.05)$ by $F$ test. Data were transformed by $\ln (x+1)$ for analysis. Means were back transformed). 
seus meristemas apicais no verão em relação ao outono $(\mathrm{P}<0,05)$, enquanto as alturas dos meristemas apicais dos perfilhos do Tanzânia não diferiram $(\mathrm{P}>0,05)$ nas duas estações.

\section{Conclusões}

O Tanzânia apresentou maiores produções que as outras duas espécies no outono, porém não diferiu das mesmas na primavera e inverno. No verão, sua produção não diferiu daquela da Setária, mas foi maior que a do Marandu.

O Tanzânia apresentou sempre elevada porcentagem de folhas e a menor altura do meristema apical, que esteve, quase sempre, rente ao solo.

A Setária apresentou os menores teores de matéria seca, independentemente das estações do ano, e a menor porcentagem de folhas no período de maior crescimento fisiológico (primavera e verão), que podem limitar o seu consumo pelos animais.

\section{Agradecimento}

À Fundação de Amparo à Pesquisa do Estado de São Paulo (FAPESP), pela bolsa de Mestrado concedida à autora principal, para execução do projeto e ao Instituto de Zootecnia em Nova Odessa, São Paulo, pelo uso da infra-estrutura e pela oportunidade concedida para a realização deste trabalho.

\section{Referências Bibliográficas}

ARONOVICH, S. O capim colonião e outros cultivares de Panicum maximum (Jacq.): Introdução e evolução do uso no Brasil. In: SIMPÓSIO SOBRE MANEJO DA PASTAGEM, 12, 1995, Piracicaba. Anais... Piracicaba: FEALQ, 1995. p.1-20.

CARRER, C.R.O., SILVEIRA, A.M., MUNIZ, C.A.S.D. et al. 1988. Efeito da aplicação de giberelina sobre a gramínea forrageira Setaria anceps Stapf. ex Massey cv. Kazungula. Rev. Faculd. Med. Vet. Zootec., 25:261-65.

CORSI, M. Manejo de plantas forrageiras do gênero Panicum. In: SIMPÓSIO SOBRE MANEJO DA PASTAGEM, 9, 1988, Piracicaba. Anais... Piracicaba: FEALQ, 1988. p.57-75.

CORSI, M., SANTOS, P.M. Potencial de produção do Panicum maximum. In: SIMPÓSIO SOBRE MANEJO DA PASTAGEM, 12, 1995, Piracicaba. Anais... Piracicaba: FEALQ, 1995. p.275-303.

COSENTINO, J.R., BUFARAH, G., PAULINO, V.T. 1985. Adaptação de plantas forrageiras no estado de São Paulo: São Luís do Paraitinga (1). Zootecnia, 23(1):23-37.

EUCLIDES, V.P.B. Valor alimentício de espécies forrageiras do gênero Panicum. In: SIMPÓSIO SOBRE MANEJO DA PASTAGEM, 12, Piracicaba, 1995. Anais... Piracicaba: FEALQ, 1995. p.245-73.

GERDES, L., WERNER, J.C., FERREIRA, T.A. et al. Produção de matéria seca e algumas características morfológicas de três capins em três idades de corte. In: REUNIÃO ANUAL DA SOCIEDADE BRASILEIRA DE ZOOTECNIA, 35, 1998, Botucatu. Anais... Botucatu: SBZ, 1998. v.2. p.263-65.

GOMIDE, J.A., OBEID, J.A., RODRIGUES, L.R. 1979. Fatores morfofisiológicos de rebrota do capim colonião (Panicum maximum). R. Soc. Bras. Zootec., 8(4):532-62.

JANK, L., SAVIDAN, Y.H. Selection for seed production and dry season forage yield in Panicum maximum germplasm. In: INTERNATIONAL GRASSLAND CONGRESS, 15, 1985, Kyoto. Proceedings... Kyoto: The Japanase Society of Grassland Science, 1985. p.119-20.

JANK, L. Potencial do gênero Panicum. In: SIMPÓSIO BRASILEIRO DE FORRAGEIRAS E PASTAGENS, 1994, Campinas. Anais... Campinas: CBNA, 1994. p.25-31.

JONES, R.J., FORD, C.W. 1972. The soluble oxalate content of some tropical grasses grown in south-east Queensland. Trop. Grassl., 6(3):201-14.

MACEDO, M.C.M. Pastagens no ecossistema cerrados: Pesquisa para o desenvolvimento sustentável. In: SIMPÓSIO SOBRE PASTAGENS NOS ECOSSISTEMAS BRASILEIROS: pesquisas para o desenvolvimento sustentável, 1995, Brasília. Anais... Brasília: SBZ, 1995. p.28-62.

PEDREIRA, J.V.S. 1973. Crescimento estacional dos capins colonião Panicum maximum Jacq., gordura Melinis minutiflora Pal de Beauv., jaraguá Hyparrhenia rufa (Ness) Stapf e pangola de Taiwan A-24 Digitaria pentzii Stent. Bol. Ind. Anim., 30(1):59-145.

RUGGIERI, A.C., RODIGUES, L.R.A., PACOLA, L.J. et al. Avaliação dos capins colonião, tanzânia 1 e marandu sob pastejo durante o período de estação de monta. In: REUNIÃO ANUAL DA SOCIEDADE BRASILEIRA DE ZOOTECNIA, 34, 1997, Juiz de Fora. Anais... Juiz de Fora: SBZ, 1997, v.2, p.237-39.

SANTOS, P.M. Estudo de algumas características agronômicas de Panicum maximum (Jacq.) cvs. Tanzânia e Mombaça para estabelecer seu manejo: Piracicaba, SP: USP, 1997. 62p. Dissertação (Mestrado em Zootecnia) - Escola Superior de Agricultura “Luiz de Queiroz”, Universidade de São Paulo, 1997.

SAS. Language guide, version 6.03 Ed. Cary: SAS Institute Inc., 1989. 530p.

SAVIDAN, Y.H., JANK, L., COSTA, J.C.G. 1990. Registros de 25 acessos selecionados de Panicum maximum. Campo Grande: CNPGC. 68p. (Documentos, 44).

SILVA, D.J. 1981. Análise de alimentos: métodos químicos e biológicos. Viçosa, MG, Imprensa Universitária/UFV. 165p.

STOBBS, T.H. 1975. Factors limiting the nutritional value of grazed tropical pastures for beef and milk production. Trop. Grassl., 9(2):141-50.

VILLARREAL, M., PASTORA, D., BRIZUELA, E. 1994. Evaluácion de gramíneas bajo pastoreo en pequeñas parcelas. Past. Trop., 16(3):9-16.
Recebido em: 28/09/1999 Aceito em: 04/02/2000 